\section{Pengaruh Electronic Word Of Mouth Dan Security Terhadap Buying Decision Melalui Electronic Trust Sebagai Variabel Mediasi}

\author{
Leli Alfiani, Ambar Lukitaningsih, Bernadetta Diansepti M \\ Fakultas Ekonomi Universitas Sarjanawiyata Tamansiswa, Yogyakarta, Indonesia \\ Email : lelialfiani02@gmail.com
}

\section{ABSTRACT}

The rapid development of technology has made business competition in the e-commerce sector even tighter. Consumer purchasing decision making is influenced by several factors such as Trust Online. Tokopedia is an Indonesian company that is engaged in e-commerce. The problems of this research are worry, uncertainty and fear of the risk received when faced withshopping online. For this reason, in this study, the researcher wanted to know what factors influence generation $Y$. Researchers narrowed down three variables, E-Wom, Security, E-Trust. This study used a quantitative research type and selected 150 people (male \& female, 18-28 years old, and using e-commerce Tokopedia) as research subjects. Researchers used the SPSS application to test the results of the study. The results showed that the most influencing factor in influencing purchasing decisions when doingshopping online application-basedwas Electronic Trust, followed by Electronic Word Of Mouth, and the last which had the least effect was Security.

Keywords: E-commerce; E-Wom; Security; E-Trust; Buying Decision

\section{ABSTRAK}

Pesatnya perkembangan teknologi membuat persaingan bisnis di bidang e-commerce semakin ketat. Pengambilan keputusan pembelian konsumen dipengaruhi oleh beberapa faktor seperti Kepercayaan Online. Tokopedia adalah perusahaan Indonesia yang bergerak di bidang e-commerce. Rumusan masalah dalam penelitian ini adalah kekhawatiran, ketidakpastian dan ketakutan akan risiko yang diterima ketika dihadapkan pada belanja online. Untuk itu dalam penelitian ini peneliti ingin mengetahui faktor-faktor apa saja yang mempengaruhi generasi Y. Peneliti mempersempit tiga variabel yaitu E-Wom, Security, ETrust. Penelitian ini menggunakan jenis penelitian kuantitatif dan memilih 150 orang (lakilaki \& perempuan, 18-28 tahun, dan menggunakan e-commerce Tokopedia) sebagai subjek penelitian. Peneliti menggunakan aplikasi SPSS untuk menguji hasil penelitian. Hasil penelitian menunjukkan bahwa faktor yang paling berpengaruh dalam mempengaruhi keputusan pembelian saat melakukan belanja online berbasis aplikasi adalah Electronic Trust, disusul Electronic Word Of Mouth, dan terakhir yang paling kecil pengaruhnya adalah Keamanan.

Kata Kunci: bisnis online, keamanan; kepercayaan; keputusan pembelian

\section{PENDAHULUAN}

Kemunculan teknologi internet di era digital saat ini telah memberikan banyak perubahan khususnya di Indonesia, internet sudah memberikan banyak manfaat dan menguntungkan bagi semua orang (Rahayu, Adi Sismanto, \& Arianto, 2020). Jaringan ini telah banyak
Electronic

Buying Decision

in Online Store

203

Submitted: MARET 2021

Accepted: APRIL 2021

\title{
JIMKES
}

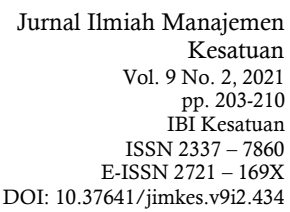


Electronic

Buying Decision

in Online Store

204 dimanfaatkan seseorang ataupun organisasi dalam menjalankan hal aktivitas sehari - harinya, salah satunya adalah untuk menjalankan usaha (Winarso, Arribe, \& Diansyah, 2017)

E-commerce banyak diminati tentu tanpa alasan, banyak keuntungan yang sudah di rasakan konsumen, konsumen bisa dengan mudahnya membeli barang setiap saat, menghemat waktu, bisa mendapatkan barang yang lebih murah dan bisa membeli suatu barang di luar wilayahnya. Inti dari kehadiran e-commerce adalah mampu mengurangi biaya administrasi dan waktu siklus proses bisnis yang meningkatkan hubungan mitra penjual dan pelanggan (Utami, 2019).

Salah satu pemain e-commerce C2C di Indonesia yaitu Tokopedia. Tokopedia dirikan pada bulan Febuari 2009 dan diluncurkan ke publik pada 17 Agustus 2009 dengan misi mencapai pemerataan ekonomi indonesia secara digital Tokopedia juga di nobatkan menjadi pemain dunia digital secara kreatif dalam mengembangkan kemampuanya di Indonesia (Rahman, Arifin, \& Bafadhal, 2018). Selain itu juga Berdasarkan data Iprice.co.id tahun 2019 data E-commerce dengan kunjungan terbanyak di Indonesia 2019 di duduki oleh Tokopedia yang menempati peringkat satu dengan situs jual beli online dengan kunjungan terbanyak. Tidak hanya itu saja penilaian data yang di akses dari Softwarseni 2019 dapat dilihat bahwa Tokopedia sendiri menduduki peringkat kedua Good Reputation dengan nilai 14.3\%. Hal ini tentu memungkinkan bahwa Penilian terhadap reputasi Tokopedia di dasarkan pada pembentukan kepercayaan online (Electronic Trust) konsumen yang di dasarkan dari beberapa faktor, diantaranya seperti Komunikasi Online (Electronic Word Of Mouth) hingga jaminan keamanan (Security) yang ada di Tokopedia.

Menurut (Budi, 2018) terdapat beberapa faktor penting yang dapat menimbulkan keputusan pembeian online E-commerce Tokopedia seperti e-wom, security dan E-Trust sehingga keputusan pembelian dapat terjadi dan menjadi faktor kunci yang mempengaruhi keputusan pembelian pelanggan dalam konteks e-business.

Generasi Y adalah sekelompok orang yang lahir pada tahun 1980 an sampai dengan tahun 2000 an (Utomo, 2019). Menurut (Subandowo, 2017), Ciri khas dari generasi millenials sendiri adalah mereka yang lahir pada masa telefon genggam, Televisi berwarna, dan juga internet yang sudah diperkenalkan, sehingga generasi ini sangat mahir dalam hal-hal yang berkaitan dengan teknologi dan digital (Andriany \&Arda, 2017) Generasi Y sebagai karakter yang serba bisa, lebih individual, lebih global, berpikiran lebih terbuka, lebih cepat terjun ke dunia kerja, lebih wirausahawan, dan tentu saja lebih ramah teknologi. Hal ini, membuat peneliti tertarik untuk mengunakan Generasi Millenial yang ada di Yogyakarta sebagai obyek penelitian

Menurut Fahmi (2018) dalam (S. puspita Dewi, 2020) Pernyataan positif atau negatif oleh potensial, aktual atau former konsumen mengenai suatu produk atau perusahaan dan disebarkan kepada orang lain atau perusahaan lain melalui internet. Electronic Word Of Mouth juga merupakan evolusi dari komunikasi interpersonal yang menuju generasi baru cyberspace (Laksamana, 2018). Selain itu menurut Hsu, Wang dan Chih (2013) dalam (Nadhira, Setyaning, \& Nugroho, 2020) menyatakan bahwa Electronic Word Of Mouth yang positif akan meningkatkan kepercayaan pelanggan dan menurunkan risiko serta mempengaruhi perilaku pembelian mereka Trust

Keamanan merupakan perasaan aman yang di dapat konsumen kepada para penyedia jasa. Keamanan merupakan sejauh mana konsumen percaya bahwa internet aman untuk transmisi informasi sensitif Delgado dalam (F.Fatoni, 2018) Keamanan sebagai kemampuan toko online dalam melakukan pengontrolan dan penjagaan keamanan atas transaksi data $(\mathrm{N}$. N. Dewi \& Ps, 2019)Perceived Ease Of Use

E-Trust adalah kesediaan suatu pihak mengandalkan pihak lain sebagai mitra untuk bertransaksi dengan percaya diri karena yakin akan memenuhi kewajibannya (Rahman, 2018). E-trust juga merupakan suatu kepercayaan umum atau sebuah niat kepercayaan yang 
membawa pihak lain dapat dipercayai atau memberikan kesediaan suatu pihak untuk peka terhadap sebuah tindakan yang dilakukkan oleh pihak lainnya (Halillah, 2018)

Menurut pendapat Amrullah (2002) dalam (Setyowati \& Suryoko, 2020), pengambilan keputusan merupakan suatu proses pemilihan dari beberapa alternatif pilihan yang sesuai dengan kepentingan tertentu dengan menetapkan satu pilihan yang dianggap menguntungkan dan menjadi prioritas

\section{Penelitian Terdahulu}

Gitnjali (2018) telah melakukan penelitian dengan judul Pengaruh E-Wom Dan E-Web Terhadap E-Loyalty Tokopedia ( Studi Pada Mahasiswa S1 Fisip Undip ). Metode penelitian Analisis data deskriptif digunakan untuk menggambarkan kondisi jawaban responden untuk masing-masing variable. Data diperoleh kuesioner yang disebarkan kepada responden sebanyak 100 kuesioner. Penelitian ini berlangsung di kampus Fakultas Ilmu Sosial dan Ilmu Politik Universitas Diponegoro. Hasil penelitian membuktikan tian dengan hasil penghitungan nilai t hitung sebesar 6,901 yang lebih besar dari t tabel sebesar 1,984 yang menunjukan bahwa E-WOM memiliki hubungan dan pengaruh yang positif dan signifikan terhadap E-Trust. Ghaisantri,F.Purbawati,Dinalestari(2020) dengan judul penelitian pengaruh Kepercayaan ( E-Trust ) terhadap Purchasing Decision. Metode penelitian digunakan untuk penelitian ini adalah explanatory research yaitu Sampel yang diambil sebanyak 100 orang yaitu yang pengguna website Zalora.co.id Hasilnya membuktikan bahwa electronic trust berpengaruh signifikan terhadap keputusan pembelian.

\section{Kerangka Pemikirian}

Kerangka pemikiran dalam penelitian ini adalah sebagai berikut :

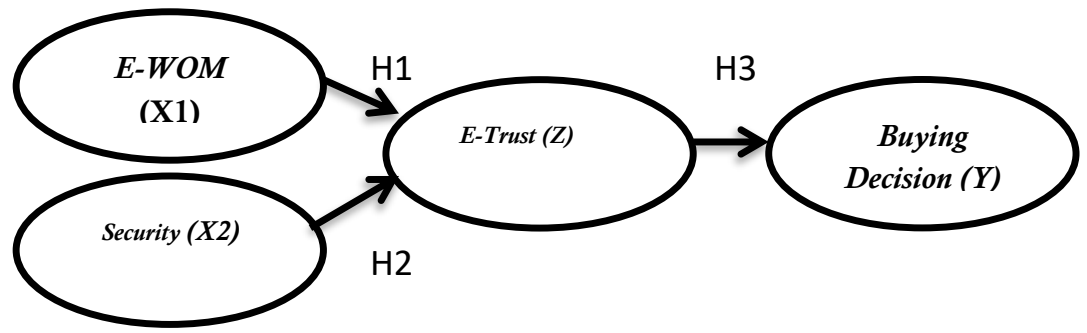

\section{Hipotesis Penelitian}

Gambar 1. Kerangka Pemikiran

Berdasarkan tujuan penelitian, perumusan masalah dan kerangka pemikiran di atas, peneliti memberikan hipotesis adalah sebagai berikut, yaitu :

1. H1 : E-Wom berpengaruh positif dan signifikan terhadap E-Trust

2. H2 : Security berpengaruh positif dan signifikan terhadap E-Trust

3. H3 : E-Trust berpengaruh positif dan signifikan terhadap Buying Decision

\section{METODE PENELITIAN}

Penelitian ini dilakukan pada Generasi Milenial yang ada di Yogyakarta. Waktu penelitian dilaksanakan pada bulan Oktober 2020 untuk uji coba terhadap instrumen penelitian dan membagikan kuesioner dan November 2020 melaksanakan analisis data dan menyusun laporan penelitian. Metode pengumpulan data yang digunakan dalam penelitian ini adalah dengan menggunakan angket atau kuesioner. Kuisioner merupakan teknik pengumpulan data yang dilakukan dengan cara memberi seperangkat pertanyaan atau pernyataan tertulis kepada responden untuk dijawabnya. Jumlah sampel dalam penelitian ini ditentukan berdasarkan pendapat dari Hair (2010) dalam (Prayustika, 2017), ukuran sampel yang ideal dan representative tergantung pada jumlah item pertanyaan pada indikator penelitian dikalikan 5-10. Jumlah pertanyaan yang digunakan sebanyak 30 item. Sehinggan jumlah responden minimal untuk penelitian ini dapat diketahui sejumlah $30 \mathrm{x}$

\author{
Electronic \\ Buying Decision \\ in Online Store
}


Electronic

Buying Decision

in Online Store
$5=150$ Responden. Jadi, jumlah sampel yang digunakan adalah 150 responden. Sumber data dalam penelitian ini adalah data primer. Data primer yaitu data yang diperoleh secara langsung dari responden yang menjadi sasaran penelitian (Rafidah, 2017). Data ini didapat dari hasil jawaban kuesioner jawaban responden oleh Konsumen Tokopedia Generasi Milenial yang ada di Yogyakarta.

\section{HASIL DAN PEMBAHASAN}

\section{Karakteristik Responden}

Responden Berdasarkan Jenis Kelamin. Dari 150 responden, kebanyakan berjenis kelamin laki-laki yaitu sebanyak 43 dan yang berjenis kelamin perempuan sebanyak 107 Tabel 1 Karakteristik Responden berdasarkan Jenis Kelamin

\begin{tabular}{cc|c|c|c} 
Genders & Frequency & Percent & Valid Percent & Cumulative Percent \\
\hline Pria & 43 & 28,7 & 28,7 & 28,7 \\
\hline Wanita & 107 & 71,3 & 71,3 & 100,0 \\
\hline Total & 150 & 100,0 & 100,0 & \\
\hline
\end{tabular}

SumbeSumber : Data primer diolah, 2020

Berdasarkan tabel 2 menunjukkan bahwa usia usia 17-20 tahun yaitu 34 orang, usia 21-24 tahun yaitu 105 orang dan usia 25-28 tahun sebanyak 11 orang

Tabel 2 Karakteristik Responden berdasarkan Usia

\begin{tabular}{cc|c|c|c} 
Ages & Frequency & Percent & Valid Percent & Cumulative Percent \\
\hline $17-20$ tahun & 34 & 22,7 & 22,7 & 22,7 \\
\hline $21-24$ tahun & 105 & 70,0 & 70,0 & 92,7 \\
\hline $25-28$ tahun & 11 & 7,3 & $71,37,3$ & 100,0 \\
\hline Total & 150 & 100,0 & 100,0 & \\
\hline
\end{tabular}

Sumber: Data primer diolah, 2020

Berdasarkan tabel 3 menunjukkan bahwa bahwa mayoritas pembeli di Tokopedia yaitu 101 orang dari responden adalah pelajar atau mahasiswa.

\begin{tabular}{c|c|c|c|c} 
Job & Frequency & Percent & Valid Percent & Cumulative Percent \\
\hline Pelajar/Mahasiswa & 101 & 67,3 & 67,3 & 67,3 \\
\hline PegawaiNegeri & 12 & 8,0 & 8,0 & 75,3 \\
\hline PegawaiSwasta & 16 & 10,7 & 10,7 & 86,0 \\
\hline Buruh & 6 & 4,0 & 4,0 & 90,0 \\
\hline Pedagang & 15 & 10,0 & 10,0 & 100,0 \\
\hline Total & 150 & 100,0 & 100,0 & \\
\hline
\end{tabular}

Sumber: Data primer diolah, 2020

Berdasarkan tabel 4 menujukan bahwa Transaksi berbelanja dalam 1 Tahun terakhir 1-5 kali yaitu 99 orang, transaksi 6-10 kali sebanyak 25 orang dan dari 11-15kali sebanyak 25 orang.

Tabel 4 Karakteristik Responden berdasarkan Transaksi

\begin{tabular}{cc|c|c|c} 
Transactions & Frequency & Percent & Valid Percent & Cumulative Percent \\
\hline $1-5$ & 99 & 66,0 & 66,0 & 66,0 \\
\hline $6-10$ & 25 & 16,7 & 16,7 & 82,7 \\
\hline $11-15$ & 25 & 16,7 & 16,7 & 99,3 \\
\hline 5 & 1 &, 7 &, 7 & 100,0 \\
\hline Total & 150 & 100,0 & 100,0 & \\
\hline
\end{tabular}

Sumber: Data primer diolah, 2020

\section{Uji Kualitas Data}

Hasil uji validitas menunjukkan bahwa variabel $E$-Wom memiliki nilai r-hitung lebih besar dar r-tabel $=0,1603$ maka dikatakan valid, dan nilai Koefisien Alpha Cronbach memiliki nilai 
lebh dari 0,06 maka dari tu dikatakan reliabel. Untuk variabel Security memiliki nilai r-hitung lebih besar dar r-tabel $=0,1603$ maka dikatakan valid, dan nilai Koefisien Alpha Cronbach memiliki nilai lebh dari 0,06 maka dari tu dikatakan reliabel. Variabel Perceived of Usefulness memiliki nilai r-hitung lebih besar dar r-tabel $=0,1603$ maka dikatakan valid, dan nilai Koefisien Alpha Cronbach memiliki nilai lebh dari 0,06 maka dari tu dikatakan reliabel. Variabel Intention memiliki nilai r-hitung lebih besar dar r-tabel =0,1966 maka dikatakan valid, dan nilai Koefisien Alpha Cronbach memiliki nilai lebih dari 0,06 maka dari tu dikatakan reliabel.

Grafik normal plot memperlihatkan data menyebar di sekitar garis diagonal dan mengikuti arah garis diago nal atau grafik histogramnya menunjukkan pola berdistribusi normal, maka grafik normal plot memenuhi asumsi normalitas. Hasil uji collinearity menunjukkan semua nilai tolerance $>0,10$ atau nilai VIF $<10$, sehingga tidak terjadi multikolinieritas. Dalam grafik scatterplot tidak membentuk pola tertentu dan menyebar disekitar titik 0 (nol). Hal ini menunjukkan bahwa tidak terjadi heteroskedastisitas.

\section{Uji Regresi Berganda}

Tabel 5 Hasil Analisis Regresi Berganda

\begin{tabular}{|c|c|c|c|c|c|c|}
\hline & \multirow{2}{*}{ Model } & \multicolumn{2}{|c|}{ Unstandardized Coefficients } & \multirow{2}{*}{$\frac{\text { Standardized Coefficients }}{\text { Beta }}$} & \multirow{2}{*}{$\mathrm{t}$} & \multirow{2}{*}{ Sig. } \\
\hline & & $\mathrm{B}$ & Std. Error & & & \\
\hline \multirow{2}{*}{1} & (Constant) & 3,459 & ,988 & & 3,501 & ,001 \\
\hline & Electronic Trust & ,323 &, 022 & ,765 & 14,443 &, 000 \\
\hline
\end{tabular}

Berdasarkan tabel 10 diatas, maka dapat diperoleh persamaan regresi sebagai berikut: $\mathrm{BD}=3,459-0,323 \mathrm{ET}+\mathrm{e}$

Persamaan tersebut menunjukkan Koefisien beta pada variabel Electronic Trust (Z) bernilai positif, maka berpengaruh positif terhadap variabel Buying Decision (Y).

\section{Hasil Uji Hipotesis}

Pengaruh Electronic Word Of Mouth terhadap Electronic Trust. Hasil pengujian signifikansi menunjukkan bahwa variabel Electronic Word Of Mouth terdapat nilai sig t sebesar 0,000 yang berarti $0,000<0,05$ dengan nilai t hitung 8,138 lebih besar dari t tabel 1,98118. Nilai tersebut dapat membuktikan bahwa Ho ditolak yang berarti bahwa Electronic Word Of Mouth berpengaruh terhadap Electronic Trust.

Pengaruh Security terhadap Electronic Trust. Hasil pengujian signifikansi menunjukkan bahwa variabel Security terdapat nilai sig t sebesar 0,000 yang berarti $0,000<0,05$ nilai t hitung 6,950 lebih besar dari t tabel 1,98118. Nilai tersebut dapat membuktikan bahwa Ho ditolak yang berarti bahwa Security berpengaruh terhadap Electronic Trust

Pengaruh Electronic Trust terhadap Buying Decision. Hasil pengujian signifikansi menunjukkan bahwa variabel Electronic Trust terdapat nilai sig t sebesar 0,000 yang berarti $0,000<0,05$ nilai t hitung 14,443 lebih besar dari t tabel 1,98118. Nilai tersebut dapat membuktikan bahwa Ho ditolak yang berarti bahwa Electronic Trust berpengaruh terhadap Buying Decision

\section{Hasil Uji Koefisien Determinan $\left(\mathbf{R}^{2}\right)$}

Tabel 6 Nilai Regresi dan $\mathrm{R}^{2}$

\begin{tabular}{lr|r|r|r} 
Model & $\mathrm{R}$ & $\mathrm{R}$ Square & Adjusted R Square & Std. Error of the Estimate \\
\hline 1 &, $868^{\mathrm{a}}$ &, 754 &, 751 & 2,562 \\
\hline
\end{tabular}

a. Predictors: (Constant), X2, X1

b. Dependent Variable: $Z$

Dari tabel 6 diatas menunjukkan adjusted $R$ square pada persamaan 1 dan 2 . Nilai adjusted $R$ square sebesar 0,751 hal ini berarti 75,1\% variabel Electronic Trust dipengaruhi Electronic Word Of Mouth dan Security sisanya 24,9\% dipengaruhi oleh variabel lain. Adjusted $R$ square persamaan 2 adjusted $R$ square sebesar 0,582 hal ini berarti 58,2\% variabel Buying Decision 
Electronic

Buying Decision

in Online Store

208 dipengaruhi i Electronic Word Of Mouth dan Security sisanya 41,8\% dipengaruhi oleh variabel lain.

\section{Pembahasan}

Pengaruh Electronic Word Of Mouth terhadap Electronic Trust. Berdasarkan dari uji persial(t hitung) Electronic Word Of Mouth menghasilkan t hitung sebesar 8,138 dengan signifikansi 0,000. Hal ini menunjukkan bahwa Electronic Word Of Mouth berpengaruh positif dan signifikan terhadap Electronic Trust karena nilai signifikansinya kurang dari 0,05. Electronic Word Of Mouth berpengaruh positif dan signifikan terhadap Electronic Trust karena nilai signifikansinya kurang dari 0,05. Maka hipotesis yang menyatakan bahwa Komunikasi Electronic Word Of Mouth berpengaruh positif dan signifikan terhadap Electronic Trust "terbukti". Hasil penelitian ini juga mendukung penelitian yang sudah dilakukan oleh (Gitanjali, 2018), (Faizal Luthfi, 2013) menyatakan bahwa terdapat pengaruh positif dan signifikan antara E-WOM terhadap E-Trust

Pengaruh Security terhadap Electronic Trust. Hasil pengujian signifikansi menunjukkan bahwa variabel Security terdapat nilai sig t sebesar 0,000 yang berarti $0,000<0,05$ nilai $t$ hitung 6,950 Nilai tersebut dapat membuktikan bahwa Ho ditolak yang berarti bahwa Security berpengaruh positif dan signifikaan terhadap Electronic Trust. Hal ini menunjukkan bahwa Security berpengaruh positif dan signifikan terhadap Electronic Trust. karena nilai signifikansinya kurang dari 0,05 . Maka hipotesis yang menyatakan bahwa Security berpengaruh positif dan signifikan terhadap Electronic Trust. "terbukti". Hasil penelitian ini juga mendukung penelitian yang sudah dilakukan (Nurhatinah, 2018) menyatakan bahwa keamanan merupakan elemen penting yang dibutuhkan oleh pelaku bisnis online untuk membangun kepercayaan konsumen.

Pengaruh Electronic Trust terhadap Buying Decision. Hasil pengujian signifikansi menunjukkan bahwa variabel Electronic Trust terdapat nilai sig t sebesar 0,000 , yang berarti $0,000<0,05$ nilai t hitung 14,443. Nilai tersebut dapat dibuktikan bahwa Ho ditolak, yang berarti bahwa Electronic Trust berpengaruh terhadap Buying Interes. Hal ini menunjukkan bahwa Electronic Trust berpengaruh positif dan signifikan terhadap buying interest karena nilai signifikansinya kurang dari 0,05 . Maka hipotesis yang menyatakan bahwa Electronic Trust berpengaruh positif dan signifikan terhadap buying interest "terbukti" Hasil penelitian ini juga mendukung penelitian yang sudah dilakukan oleh ((Ghaisantri \& Purbawati, Dinalestarii, 2020) , (Setyowati \& Suryoko, 2020) yang menunjukkan bahwa E-TRUST berpengaruh positif terhadap Keputusan Pembelian. Jadi Pengaruh E-Trust berpengaruh secara positif dan signifikaan terhadap Buying DecisionPengaruh Komunikasi Trust terhadap Perceived of Usefulness.

\section{PENUTUP}

Berdasarkan hasil penelitian dan pembahasan penelitian diatas dapat disimpulkan sebagai berikut:

1. Terdapat pengaruh positif E-Wom terhadap E-Trust dalam menggunakan Tokopedia pada Generasi Y di Yogyakarta

2. Terdapat pengaruh positif Security terhadap E-trust dalam menggunakan Tokopedia pada generasi Y di Yogyakarta

3. Terdapat pengaruh positif Electronic Trust terhadap Buying Decision dalam menggunakan Tokopedia Pada Generasi Y di Yogyakarta

\section{DAFTAR PUSTAKA}

[1] Neo-bis, J., \& Pradana, M. (2015). KLASIFIKASI JENIS-JENIS BISNIS ECOMMERCE. 9(2), 32-40. 
[2] Dewi, S. puspita. (2020). Pengaruh Komunikasi Electronic Word Of Mouth Dan Security Terhadap Buying Interest Melalui Trust Sebagai Variabel Intervening Pada Online Shop Shopee (Studi Kasus Pada Mahasiswa Ust Yogyakarta). Journal of Chemical Information and Modeling, 53(9), 1689-1699.

[3] Rafidah, I. (2017). ANALISIS KEAMANAN KEMUDAHAN DAN KEPERCAYAAN TERHADAP KEPUTUSAN PEMBELIAN SECARA ONLINE DI LAZADA Sekolah Tinggi Ilmu Ekonomi Indonesia (STIESIA) Surabaya. 6.

[4] Halillah, R. A. dan lil. (2018). PENGARUH E-TRUST TERHADAP E-LOYALTY. 1204-1213.

[5] Chellappa, R. K., \& Pavlou, P. A. (2002). Perceived information security, financial liability and consumer trust in electronic commerce transactions. Logistics Information Management, 15(5/6), 358-368. https://doi.org/10.1108/09576050210447046

[6] Lin, A., \& Foster, J. (2013). Electronic Word-of-Mouth (eWOM) and its influence on book purchasing decisions: A study of the Anobii Digital Bookshelf. Consumer Information Systems and Relationship Management: Design, Implementation, and Use, 156172. https://doi.org/10.4018/978-1-4666-4082-5.ch009

[7] Budi, W. P. (2018). Analisis Perkembangan E-commerce Dalam Mendorong Pertumbuhan Ekonomi Wilayah di Indonesia.

[8] Rafidah, I. (2014). ANALISIS PENGARUH KEPERCAYAAN, KEAMANAN, KUALITAS PELAYANAN, DAN PERSEPSI AKAN RISIKO TERHADAP KEPUTUSAN PEMBELIAN MELALUI SITUS JEJARING SOSIAL.

[9] Nadhira, A., Setyaning, A., \& Nugroho, S. S. (2020). The influence of website characteristics on customer satisfaction and E-WOM in Indonesia. 24(2), 148-167. https://doi.org/10.20885/jsb.vol24.iss2.art5

[10] Aisyah, D., \& Engriani, Y. (2019). Pengaruh Reputasi, Kualitas Informasi, dan e-WOMt erhadap Minat Beli pada Situs Jual Beli Online Tokopedia yang Dimediasi oleh Kepercayaan Pelanggan. 01, 48-59.

[11] Sari, A. P., \& Rahmidani, R. (2019). Pengaruh E-Word Of Mouth Dan E-Trust Terhadap E-Purchase Decision Mahasiswa Universitas Negeri Padang Pada Marketplace Lazada. 2, 666677.

[12] Mulyana, M. (2012). Consumer Behaviour: Sukses Dengan Memahami Konsumen.

[13] Mulyana, M., Hakim, D. B., \& Hartoyo, S. (2020). Entrepreneurial Activities And Performance Of Rice Farming In Bojongpicung Sub-District, Cianjur Regency. European Journal of Molecular \& Clinical Medicine, 7(3), 4528-4535.

[14] Riwoe, F. L. R., \& Mulyana, M. (2020). Model Struktural Kepuasan Mahasiswa Dengan Kualitas Pelayanan Sebagai Variabel Eksogen. Jurnal Ilmiah Manajemen Kesatuan, 8(1), 1-8.

[15] Prayustika, P. A. (2017). Kajian Literatur: Manakah Yang Lebih Efektif? Traditional Word of Mouth Atau Electronic Word of Mouth. Matrix: Jurnal Manajemen Teknologi Dan Informatika, 6(3), 168.

[16] Winarso, D., Arribe, E., \& Diansyah, R. (2017). PEMANFAATAN INTERNET SEHAT MENUJU. 1(1), 19-23.

[17] Noegraheni, H. P. D. E. (2014). TERHADAP REPURCHASE PADA KASKUS Hartiwi Prabowo ; Darman ; Enny Noegraheni. Binus Business Review, 5, 301-314.

[18] Purbawati, P. D. (n.d.). Abstraksi: Penelitian ini bertujuan untuk mengetahui pengaruh antara variabel e-service quality dan e-security seals sebagai variabel $x$ terhadap e-satisfaction sebagai variabel y melalui variabel $z$ yakni keputusan pembelian. Tipe penelitian ini adalahe.

[19] Laksamana, A. dan P. (2018). PENGARUH SOCIAL MEDIA PROMOTION DAN ELECTRONIC WORD OF MOUTH TERHADAP KEPUTUSAN PEMILIHAN PADA PERGURUAN TINGGI Azmar. 
Electronic

Buying Decision

in Online Store

210
[20] Purnami, N. M., \& Nurcaya, I. N. (2015). PENGARUH E-TRUST , PERCEIVED USEFULNESS DAN E-SATISFACTION TERHADAP ONLINE. 1-8.

[21] Sudradjat, S., \& Amyar, F. (2020). PKM Uji Kompetensi Bidang Keahlian Akuntansi di SMK Pembangunan Kota Bogor. Jurnal Abdimas Dedikasi Kesatuan, 1(1), 37-42.

[22] Sudjatmika, F. V. (2017). Pengaruh Harga, Ulasan Produk, Kemudahan, dan Keamanan Terhadap Keputusan Pembelian Secara Online di Tokopedia.com. Agora, 5(1), 1-7. Retrieved from http://studentjournal.petra.ac.id/index.php/manajemenbisnis/article/view/5227\%0Ahttp://studentjournal.petra.ac.id/index.php/manajem en-bisnis/article/view/5227/4814 